\title{
The Effect of pH-adjusted Gold Colloids on the Formation of Gold Clusters over APTMS-coated Silica Cores
}

\author{
Sang-Eun Park, Min-Yim Park, Po-Keun Han, and Sang-Wha Lee* \\ Dept. of Chemical and Bio Engineering, Kyntgwon University, Seongnam, Gyeonggi 461-701, Korea \\ "E-mail: lswha@kyungwonac.kr \\ Received Mav 18,2006
}

\begin{abstract}
$\Lambda \mathrm{n}$ electrostatic interaction is responsible for the attachment of gold seeds of $1-3 \mathrm{~nm}$ onto $\Lambda$ PTMS (3aminopropyl trimethoxysilane)-coated silica cores in the formation of gold clusters. $\Lambda$ surface plasmon resonance and morphology of gold clusters were significantly affected by the pII of gold colloids prepared by TIIPC reducing agent. Gold colloids of alkaline pII induced the heterogeneous deposition of gold seeds onto the silica nanoparticles, probably due to the continuous reduction of residual gold ions during the attachment process. Gold colloids of acidic pII induced the monodisperse deposition of gold seeds, consequently leading to the formation of smooth gold layer on the silica nanoparticles surface. The gold nanoshells (core radius $=80$ $\mathrm{nm}$ ) prepared by gold colloids of pII 3.1 exhibited the more red-shift and relatively stronger intensity of plasmon absorption bands, compared with gold nanoshells prepared by alkaline gold colloids of pII 9.7 .
\end{abstract}

Key Words : pH, Gold colloids, Plasmon resonance, Silica, Nanoshell

\section{Introduction}

Recent research has been focused on the fabrication of a new hybrid nanocomposite that consists of a dielectric silica core surrounded by a thin gold shell, particularly for the precise control of optical and electrical properties. ${ }^{1,2}$ This hybrid nanoparticle, so called a gold nanoshell, can exhibit a strong optical resonance, typically shifted to much longer wavelength than the corresponding optical resonance of gold nanoparticles. ${ }^{3}$ Surface plasmon resonance (SPR) is collective oscillation of the conduction electrons. The plasmon resonance spectra depend on a variety of factors, such as the size, and shape of the nanoparticles, interparticle interactions, and their dielectric environment. ${ }^{4.5}$ The plasmon-derived optical resonance of gold nanoshell is dependent on the relative dimensions of the silica core and gold thin layer. By simply adjusting the core-shell ratio, this optical resonance can be positioned over hundreds of nanometers in wavelength, across the visible into the infrared spectrum. ${ }^{6.7}$ Also, the optical resonance of gold nanoshell depends on the dielectric constant of core materials across the metal interface according to the classical Mie scattering theory. ${ }^{8}$

A gold layer on the silica core possesses optical and electrical properties that are distinct from those of both the bulk phase and individual molecules. These features render nanoshells for applications in optoelectronics, biophotonics, diagnostics, catalysis, and conducting polymers. ${ }^{9-13}$ Halas and co-workers exploited the biomedical applications of thermal ablative cancer therapy, immunoassays, and photo thermally-activated drug delivery. Even though there are wellestablished methods for the fabrication of gold nanoshells with dielectric cores, there are few reports on the attachment process of gold seeds on the silica surface that is a key step for producing a smooth and thin gold layer. ${ }^{1+16}$
The exposure of gold seeds to APTMS-functionalized silica surface led to a higher initial coverage followed by the monolayer coverage of gold nanoparticles up to $25-30 \%$ due to electrostatic repulsion between the nanoparticles. ${ }^{17.18}$ Westcott $e t$ al. immobilized citrate-gold nanoparticles onto silica nanoparticles and then the surface of the adsorbed gold nanoparticles were functionalized with 4-aminobezenethiol, leading to the moderate coverage of gold nanoparticles. ${ }^{19}$ They also exhibited the self-assembly of gold clusters on the functionalized silica surface by adjusting the volume ratio of water and ethanol mixtures. ${ }^{20}$ Prasad et al. reported that surface coverage of gold-deposited PS (Polystyrene) was increased more than $30 \%$ by reducing the size of gold nanoparticles and the gold-to-PS ratio. ${ }^{15}$

In the present work, we systematically investigated the attachment of gold seeds onto the APTMS-functionalized silica cores by adjusting the $\mathrm{pH}$ of THPC-induced gold colloids. The zeta-potential of colloidal particles was measured by ELS-8000 (Zeta-meter) to elucidate the electrostatic interactions between gold nanoparticles and functionalized silica surface. The morphology of gold-silica nanocomposites was characterized with TEM and SEM. The red-shift of plasmon absorption peak was confirmed by UVVis spectroscopy.

\section{Experimental Section}

Materials. All reagents were purchased from Aldrich and used as received: 3-Aminopropyl Trimethoxysilane (APTMS, 97\%), Tetraethyl Otho-silicate (TEOS, 99.999\%), Tetrakis (Hydroxymethyl) Phosphonium Chloride (THPC, 80\% solution), Ammonium Hydroxide $\left(\mathrm{NH}_{4} \mathrm{OH}, 30 \%\right)$, Formaldehyde ( $\mathrm{HCOH}, 37 \%$ ), Hydrogen Tetra-chloroaurate (III) Hydrate ( $\left.\mathrm{HAuCl}_{4}, 99.99 \%\right)$, Potassium Carbonate $\left(\mathrm{K}_{2} \mathrm{CO}_{3}\right.$, $99.7 \%)$, Absolute Ethanol $\left(\mathrm{C}_{2} \mathrm{H}_{5} \mathrm{OH}, 99.5 \%\right)$, Sodium Hydr- 


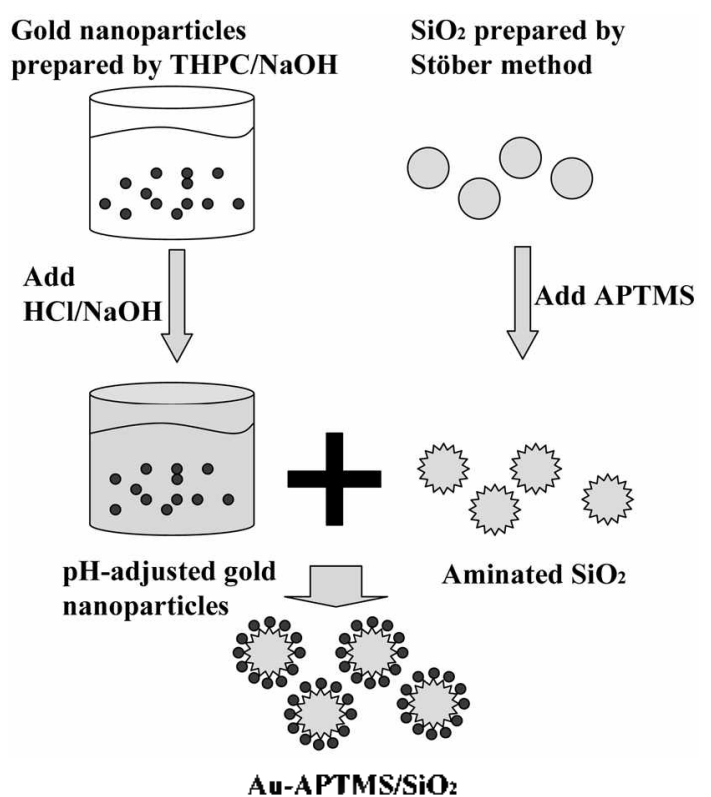

Figure 1. Schematic diagran of the formation of gold clusters over the APTMS-coated silica cores.

oxide (NaOH, Semiconductor grade). HPLC-grade water was used at every stage of reaction and washing.

Synthesis. Colloidal silica nanoparticles (dia. $=80 \mathrm{~nm}$ ) were prepared at $48{ }^{\circ} \mathrm{C}$ by the Stöber method. ${ }^{21}$ Ammonium solution $(30 \mathrm{wt} \%)$ of $3.9 \mathrm{~mL}$ was used as a catalyst in the formation of colloidal silica particles. And then, $1.5 \mathrm{~mL}$ TEOS solution was added into $45 \mathrm{~mL}$ ethanol solution and stirred ovenight. The condensation of tetraethyl orthosilicate generally started within $10 \mathrm{~min}$, which was easily observed by the change of the solution from colorless to opaque.

To prepare gold colloids of $1-3 \mathrm{~nm}, 0.5 \mathrm{~mL}$ of $1.0 \mathrm{M}$ $\mathrm{NaOH}$ and THPC $(1.0 \mathrm{~mL}$ of $50 \mathrm{mmol} / \mathrm{L}$ aqueous solution) were mixed with $45 \mathrm{~mL} \mathrm{HPLC}$ grade water, and $2.0 \mathrm{~mL}$ of $1.0 \mathrm{wt} \%$ tetrachlroloaurate (III) trihydrate was added quickly into the mixed solution. ${ }^{22}$ An excess of APTMS was added to the solution of silica nanoparticles with vigorous stirring for $2 \mathrm{hr}$. To enhance the covalent bonding of APTMS groups with the silica surface, the solution was gently mixed at 70 ${ }^{\circ} \mathrm{C}$ for $1 \mathrm{hr}^{23}$ And then $0.5 \mathrm{~mL}$ of functionalized silica nanoparticles was added to gold colloids for the attachment of gold seeds onto the silica surface.

The formation of gold layer on gold-deposited silica (AuAPTMS/SiO 2 ) was conducted by the subsequent reduction of gold salts. In a reaction flask, $25 \mathrm{mg}$ of potassium carbonate was added to $100 \mathrm{~mL}$ of HPLC grade water. After $10 \mathrm{~min}$ of stirring, $1.5 \mathrm{~mL}$ of $1.0 \mathrm{wt} \% \mathrm{HAuCL}_{4}$ was added. A color of solution was slowly changed from yellow to colorless. $200 \mu \mathrm{L}$ of $\mathrm{Au}-\mathrm{APTMS} / \mathrm{SiO}_{2}$ was added to a vigorously stirred $4 \mathrm{~mL}$ of colorless solution, and fornaldehyde was subsequently added as a reduction agent. The fabrication process of gold-deposited silica nanoparticles was schematically drawn in Figure 2.

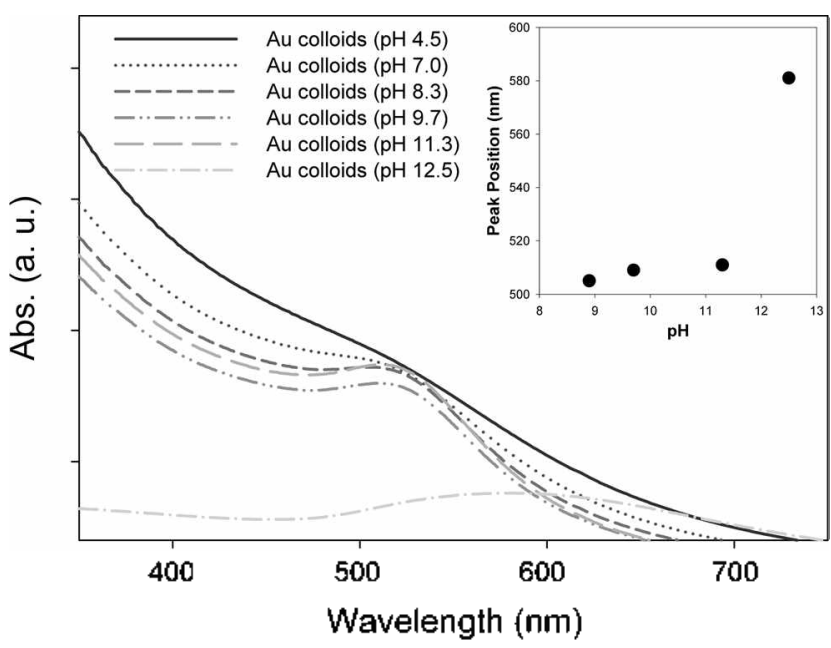

Figure 2. UV-Vis spectra of $\mathrm{pH}$-adjusted gold colloids at different $\mathrm{pH}$ values.

\section{Results and Discussion}

The fabrication of gold nanoshell consists of two major steps: i) The first is to prepare gold-deposited silica cores, ii) The second is to grow gold seeds attached on the silica nanoparticle surface by the subsequent reduction of gold ion salts. The $\mathrm{pH}$ adjustment of gold colloids was employed in the first attachment process, i.e., gold-deposited silica was prepared by reacting APTMS-functionalized silica with $\mathrm{pH}-$ adjusted gold colloids when all other experimental conditions were kept constant.

Gold colloids prepared by THPC reducing agent exhibited the zeta-potential of $-40.2 \pm 7.2 \mathrm{mV}$ at $\mathrm{pH} 9.7$. To optimize the attachment (or deposition) process, the $\mathrm{pH}$ of gold colloids was adjusted over the broad ranges of $\mathrm{pH}$ 3-12 corresponding to the change of zeta-potentials from $\mathrm{ca} .-30$ to $-50 \mathrm{mV}$. Figure 2 exhibited the UV-Vis spectra of $\mathrm{pH}-$ adjusted gold colloids. The plasmon resonance of THPC gold colloids was more suppressed with the decrease of solution $\mathrm{pH}$, probably due to finite-size effect of metal dimensions. ${ }^{24}$ The spectral position of gold colloids was slightly shifted by $6 \mathrm{~nm}$ (from $505 \mathrm{~nm}$ to $511 \mathrm{~nm}$ ) by the increase of solution $\mathrm{pH}$ from $\mathrm{pH} 7.0$ to $\mathrm{pH} 11.3 .^{25}$ However, gold colloids of pH 12.4 exhibited a distinct red-shift with a significant reduction of peak intensity due to heavy agglomeration of gold nanoparticles.

To attach the gold colloids of $1-3 \mathrm{~nm}$ onto the silica nanoparticles with negative charges, silica nanoparticle surface should be modified by self-assembled monolayer that can give positive zeta-potentials. The zeta potentials of silica nanoparticles were measured in the range of $-70 \sim-80$ mV. APTMS-modified silica nanoparticles exhibited the zeta-potential of $c a+40 \mathrm{mV}$ (data not shown). The attachment of gold colloids onto the silica nanoparticles was conducted by the electrostatic attractions between gold and silica nanoparticles with different charges. ${ }^{2}$

APTMS-modified silica nanoparticles were then added to 


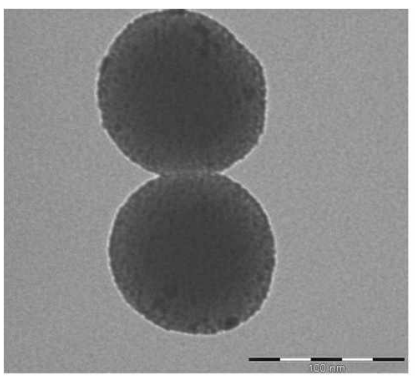

(a)

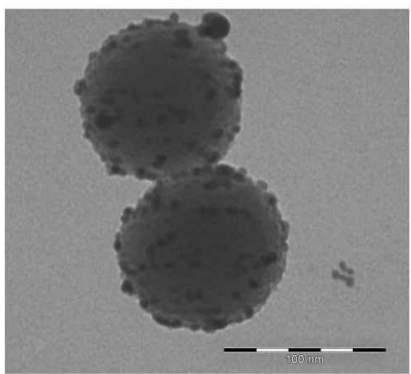

(c)

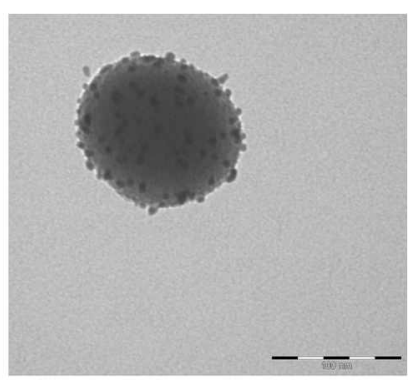

(b)

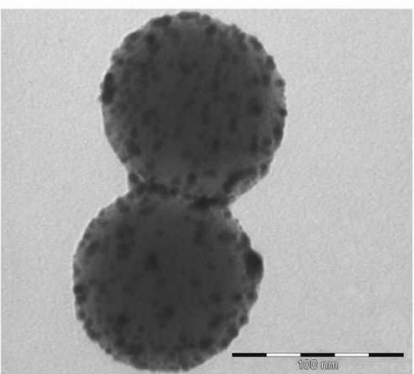

(d)
Figure 3. TEM images of Au-ATTMS $/ \mathrm{SiO}_{2}$ (core $\mathrm{dia}=80 \mathrm{~nm}$ ) prepared by $\mathrm{pH}$-adjusted gold colloids: (a) $\Lambda \mathrm{u}-\Lambda \mathrm{PTMS} / \mathrm{SiO}_{2}$ by $\mathrm{\Lambda u}$ colloids ( $\mathrm{pH} 3.1$ ), (b) $\Lambda \mathrm{u}-\Lambda$ PTMS/ $/ \mathrm{SiO}_{2}$ by $\Lambda \mathrm{u}$ colloids ( $\mathrm{pH} 7.0$ ), (c) Au-AJTMS/SiO by Au colloids (pH 9.7), (d) Aul-ATTMS/SiO 2 by Au colloids ( $\mathrm{pH} \mathrm{10.3)}$.

gold colloids of various $\mathrm{pH}$ values. The silica nanoparticles attached by gold colloids were named as Au-APTMS/SiOn.

As shown in Figure 3(a), Au-APTMS/SiO 2 prepared by gold colloids of $\mathrm{pH} 3.1$ exhibited a monodisperse deposition of gold seeds on the silica nanoparticles, of which the size was ranged in $2 \mathrm{~nm}-4 \mathrm{~nm}$. At $\mathrm{pH}>7$ of gold colloids, as shown in Figure 3(b), not only single gold nanoparticles but also some gold clusters were observed on the silica surface. At high $\mathrm{pH}$ values of gold colloids, agglomerated gold clusters of $5-10 \mathrm{~nm}$ were predominant on the silica nanoparticles surface. The cluster size was generally increased by raising the $\mathrm{pH}$ values of gold colloids. At $\mathrm{pH}>12$ of gold colloids, a vast agglomeration of gold nanoparticles was observed on the silica surface (data not shown).

As seen in Table 1, gold-deposited silica nanoparticles prepared by gold colloids of $\mathrm{pH} 3.1$ exhibited the higher zeta-potentials in negative values compared with those prepared by gold colloids of other alkaline $\mathrm{pH}$, indicating the high number of gold seeds on the gold-deposited silica. The low attachment of gold seeds shown in Figure $3(\mathrm{c}-\mathrm{d})$ was caused by the increase of electrostatic repulsion between gold colloids of alkaline $\mathrm{pH}$ with more negative charges. In addition, the heterogeneous deposition of gold seeds seemed to be induced by the continuous reduction of residual gold ions in the presence of excessive $\mathrm{OH}^{-}$ions.

$$
\begin{aligned}
& \mathrm{P}\left(\mathrm{CH}_{2} \mathrm{OH}\right)_{4}{ }^{\prime}+\mathrm{OH}^{-} \rightarrow \mathrm{P}\left(\mathrm{CH}_{2} \mathrm{OH}\right)_{3}+\mathrm{CH}_{2} \mathrm{O}+\mathrm{H}_{2} \mathrm{O} \\
& \mathrm{P}\left(\mathrm{CH}_{2} \mathrm{OH}\right)_{3}+2 \mathrm{H} 2 \mathrm{O} \rightarrow \mathrm{O}_{2} \mathrm{P}\left(\mathrm{CH}_{2} \mathrm{OH}\right)_{3}+2 \mathrm{H}_{2}
\end{aligned}
$$

According to equations (1) \& (2), THPC is a powerful reducing agent enough to make gold seeds by the derivation of formaldehyde at alkaline condition. ${ }^{26}$ On the other hand, the addition of $\mathrm{H}^{\prime}$ ions induces the decrease of THPC reducing power via preventing the release of a formaldehyde reducing molecule. Therefore, the formation of large gold clusters on the silica surface can be facilitated by the enhanced reducing power of THPC in the presence of excessive $\mathrm{OH}^{-}$ions, whereas monodisperse deposition of gold seeds can be facilitated by the addition of $\mathrm{H}^{\prime}$ ions due to the inhibition of reducing power of THPC.

Au-APTMS/SiO 2 prepared at various $\mathrm{pH}$ values of gold colloids exhibited the different absorption peaks of UV-Vis spectra, as shown in Figure 4. Au-APTMS/ $/ \mathrm{SiO}_{2}$ prepared by gold colloids of $\mathrm{pH} 3.1$ exhibited the very slight absorption peak at ca. $521 \mathrm{~nm}$. Au-APTMS/SiO2 prepared by gold colloids of alkaline $\mathrm{pH}$ exhibited a distinct spectral intensity of plasmon bands. The difference of the plasmon absorption bands among gold-deposited silica nanoparticles reflected the size of gold clusters that is strongly dependent on the

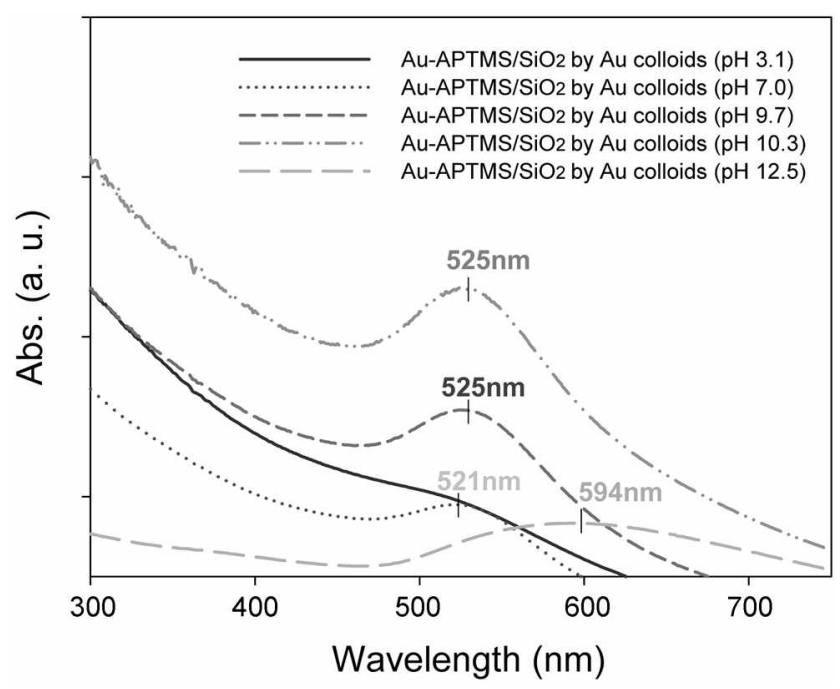

Figure 4. UV- Vis spectra of $\Lambda \mathrm{u}-\Lambda \mathrm{PTMS} / \mathrm{SiO}=$ prepared by $\mathrm{pH}-$ adjusted gold colloids at different $\mathrm{pH}$ values.

Table 1. Physicochenical characteristics of gold colloids and gold-deposited silica nanoparticles

\begin{tabular}{lcccc}
\hline Characteristics & $\mathrm{pH} 3.1$ & $\mathrm{pH} 7.0$ & $\mathrm{pH} 9.7$ & $\mathrm{pH} 10.3$ \\
\hline Zeta-potential of gold colloids $(\mathrm{mV})$ & $-28.8 \pm 5.8 \mathrm{mV}$ & $-40.2 \pm 11 \mathrm{mV}$ & $-40.2 \pm 7.2 \mathrm{mV}$ & $-49.25 \pm 10 \mathrm{mV}$ \\
Zeta-potential of Au/APTMS-SiO $(\mathrm{mV})$ & $-42.4 \pm 4.5 \mathrm{mV}$ & $-32.5 \pm 0.6 \mathrm{mV}$ & $-30.4 \pm 7.4 \mathrm{mV}$ & $-37.5 \pm 2.0 \mathrm{mV}$ \\
Position of plasmon peak of Au/APTMS-SiO & $515 \mathrm{~nm}$ & $521 \mathrm{~nm}$ & $525 \mathrm{~nm}$ & $525 \mathrm{~nm}$ \\
Absorption difference of Au/APTMS-SiO $\left(\Delta \lambda^{2}\right)$ & $0.00^{5}$ & 0.09 & 0.22 & 0.38 \\
\hline
\end{tabular}

"Absorption difference, $\Delta \lambda$, indicated a difference between the heights of plasnon absorption bands. " $\Delta \lambda$ at pII 3.1 wass assumed to be negligible. 


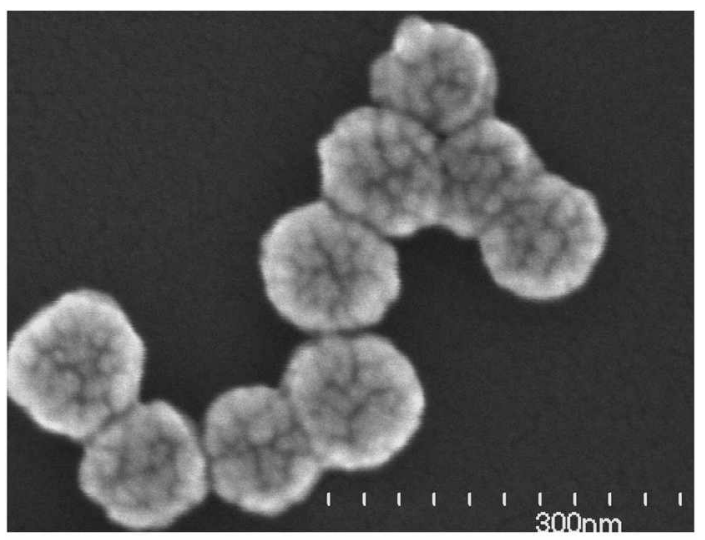

(a)

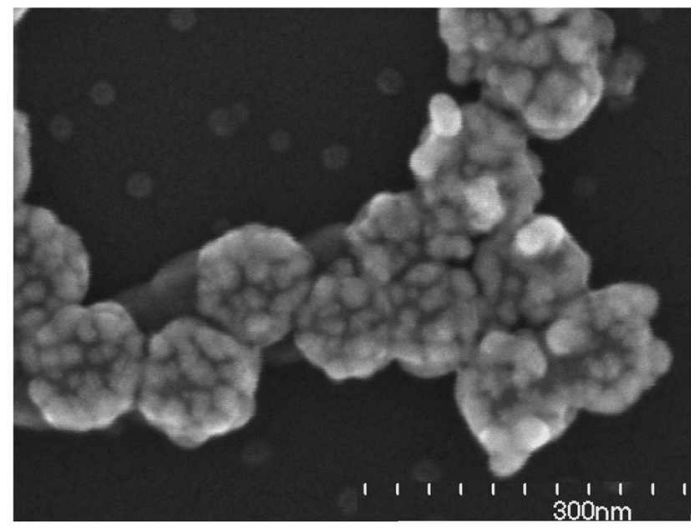

(b)

Figure 5. SEM images of gold nanoshells prepared by $\mathrm{pH}$-adjusted gold colloids: (a) gold nanoshell by $\Lambda \mathrm{u}$ colloids ( $\mathrm{pH} 3.1$ ), (b) gold nanoshell by $\mathrm{Au}$ colloids ( $\mathrm{pH} 9.7$ ).

peak intensity and red-shift of absorption bands.

The gold-deposited silica was centrifuged several times to remove the residual impurities and re-dispersed in water for the subsequent reaction with gold ion salts in order to fabricate the gold nanoshell. The attached gold seeds onto the silica cores played as nucleation sites to induce the coalescence between neighbouring gold clusters. ${ }^{714}$ The monodisperse deposition of gold seeds (or high adsorbed gold seeds) resulted in the smooth surface morphology of gold nanoshells, as shown in Figure 5(a). On the other hand, heterogeneous deposition of gold seeds (or low adsorbed gold seeds) resulted in the relatively incomplete coverage of gold layer on the silica cores, as shown in Figure 5(b). Gold nanoshells prepared by gold colloids of $\mathrm{pH} 12.4$ exhibited no plasmon resonance due to heavy agglomerations between gold nanoparticles (data not shown).

As shown in Figure 6, gold nanoshells prepared by gold colloids of $\mathrm{pH} 3.1$ exhibited the relatively stronger plasmon resonance (stronger intensity and more red-shift) in comparison to those prepared by gold colloids of $\mathrm{pH} 9.7$. If the gold shell was not completely covered as previously shown in Figure 5(b), the peak intensity and red-shift of plasmon resonance was fairly lessened.

Conclusively, pH-adjusted gold colloids make it possible

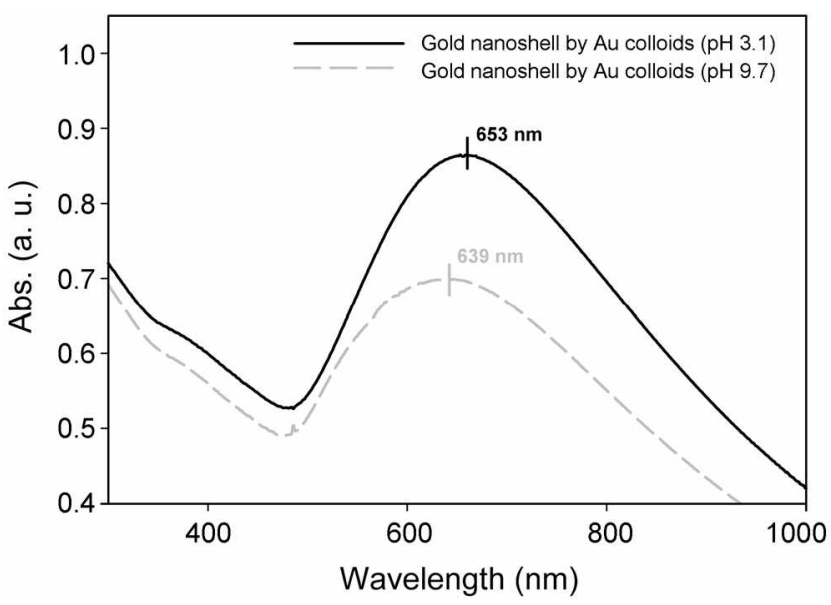

Figure 6. UV-Vis spectra of gold nanoshells prepared by $\mathrm{pH}-$ adjusted gold colloids at different $\mathrm{pH}$ values.

to control the morphology of gold-deposited silica and fabricate a strong NIR-absorbing gold nanoshell very reproducibly. That is, higher adsorbed gold nucleates prepared by gold colloids of $\mathrm{pH} 3.1$ led to smooth and continuous gold layer onto the silica cores via a nucleate-mediated coalescing process, consequently leading to the stronger plasmon resonance of gold nanoshell.

\section{Conclusion}

A surface morphology and plasmon resonance of gold clusters on the colloidal silica spheres were strongly affected by the $\mathrm{pH}$ of gold colloids in the fabrication process of gold nanoshell. THPC-induced gold colloids at alkaline $\mathrm{pH}(\mathrm{pH}$ 9-11) induced larger size of gold clusters onto the APTMSfunctionalized silica cores, probably due to the continuous reduction of residual gold ions in the presence of excessive $\mathrm{OH}^{-}$ions. The monodisperse deposition of gold seeds by gold colloids of $\mathrm{pH} 3.1$ resulted in more red-shift and relatively stronger plasmon absorption bands of gold nanoshells. Conclusively, high adsorbed gold nucleates can easily lead to the smooth morphology of gold layer and more red-shift of plasmon absorption bands.

Acknowledgements. The work was supported by GRRC Project of Gyeonggi Provincial Govemment and partially supported by Regional Innovation Center for Nanoparticles at Kyungwon University.

\section{References}

I. Zhu, M.; Qian, G.; Hong, Z.; Wang, Z.; Fan, X.; Wang, M. J. Phys. Chem, of Solids 2005, 66, 748.

2. Pham, T.; Jackson, J. B.; Halas, N. J.; Lee, T. R. Langmir 2002. 18,4915 .

3. Jackson, J. B.; Halas, N. J. J. Phys. Chem. 2001, 105, 2743.

4. Kreibig, U.; Vollmer, M. Optical Properties of Metal Clusters in Springer Series in Materials Science; Springer-Verlag: Berlin, Germany, 1995.

5. Halas, N. J. Plasmonics: Metallic Nanostrictures and Their Optical 
Properties in Proceedings of SPIE (Vol. 5221); Bellinghsm: USA, 2003.

6. Averitt, R. D.; Oldenburg, S. J.; Westcott, S. L.; Lee, T. R.; Halas, N. J. NASA Conference Publication 1999, 209092, 301.

7. Oldenburg, S. J.; Averitt, R. D.; Westcou, S. L.; Halas, N. J. Chem. Phy: Letters 1998, 288, 243.

8. Prodan, E.; Radloff, C.; Halas, N. J.; Nordlander, P. Science 2003, 302,419 .

9. Pol, V. G.; Gedanken, A.; Calderon-Moreno, J. Chem. Mater. $2003,15,1111$.

10. Kim, H. J.; Kang, J.; Park, D. G.; Kweon, H. J.; Klabunde, K. J. Bull. Korean Chem. Soc. 1997, 18, 831.

II. Jang, N. H. Bull. Korean Chem. Soc. 2004, 25, 1392.

12. Wang, Y.; Xie, X.; Wang, X.; Ku, G.; Gill, K. L.; O'Neal, D. P.; Stoica, G; Wang, L. V. Nano Leffers 2004, 4, 1689.

13. Sershen, S. R.; Westcoth, S. L.; Halas, N. J.; West, J. L. J. of Bioned. Mater: Res, 2000, 51, 293.

14. Caruso, F, Atr, Mater, 2001, 13,11 .

15. Shi, W.; Sahoo, Y.; Swihart, M. T.; Prasad, P. N. Langmuir 2005, 21,1610 .
16. Lim, Y. T.; Park, O. O.; Jung, H. T. J. Colloid Interface Sci. 2003, $263,449$.

17. Grabar, K. C.; Smith, P. C.; Musick, M. D.; Davis, J. A.; Walter, D. G.; Jackson, M. A.; Guthrie, A. P.; Natan, M. J. J. Am. Chem. Soc. 1996, 1/8, 1148 .

18. Grabar, K. C.; Allison, K. J.; Baker, B. E.; Bright, R. M.; Brown, K. R.; Freeman, R. G.; Fox, A. P.; Keating, C. D.; Musick, M. D.; Natan, M. J. Langmuir 1996, 12, 2353.

19. Westcott, S. L.; Oldenburg, S. J.; Lee, T. R.; Halas, N. J. Chenical Physics Letters 1999, 300, 65I.

20. Westcoth, S. L.; Oldenburg, S. J.; Lee, T. R.; Halas, N. J. Langmir $1998,14,5396$.

21. Stöber, W.; Fink, A. J. Colloid Interface Sci. 1967, $26,62$.

22. Duff, D. G.; Baker, A.; Edwards, P. P. J. Chem. Soc, Chent. Coninum 1993, 96.

23. van Blaaderen, A.; Vrij, A. J. Joumal of Colloid Interface Sci. $1993,156, \mathrm{I}$.

24. Kreibig, U.; Genzel, L. Swif. Sci, 1985, 156, 678.

25. Brown, K. R.; Walter, D. G; Natan, M. J. Chem. Mater 2000, /2, 306.

26. Duff, D. G.; Baiker, A. Langmuir 1993, 9, 2301. 